\title{
Atividade do mototaxista: riscos e fragilidades autorreferidos
}

\author{
Activity of motorcycle taxi driver: risks and weaknesses self referred \\ Actividad de moto taxis: riesgos y fragilidades auto referidos
}

Mariéli Brum da Silva', Michele Braga de Oliveira', Rosane Teresinha Fontana'

' Universidade Regional Integrada do Alto Uruguai e das Missões, Curso de Enfermagem. Santo Ângelo-RS, Brasil.

Submissão: 16-08-2010 Aprovação: 27-01-2012

\section{RESUMO}

Pesquisa descritiva, de abordagem qualitativa que teve como objetivo identificar riscos ocupacionais e fragilidades autorreferidas por mototaxistas. Os dados foram coletados, no primeiro semestre de 2010, mediante entrevistas junto a doze mototaxistas, convidados a participar, e que trabalham em dois pontos centrais de um município do interior do estado do Rio Grande do Sul. Os dados foram tratados por meio da análise temática, a partir da qual foram reveladas cinco categorias. De acordo com a percepção dos sujeitos, os acidentes e os assaltos representam os maiores riscos da profissão. Pode-se inferir que ações de educação em saúde e de prevenção de agravos podem ser estratégias governamentais e não governamentais que agregam valor à saúde e segurança destes trabalhadores.

Descritores: Riscos ocupacionais; Saúde do trabalhador; Transportes; Trabalhadores.

\section{ABSTRACT}

Descriptive research, with qualitative approach, that aimed to identify occupational hazards and weaknesses self-reported by motorcycle drivers. Data were collected in the first half of 2010 through interviews with twelve motorcycle drivers, invited to participate and work on two central points of a municipality in the state of Rio Grande do Sul, Brazil. Data were analyzed using thematic analysis, from which emerged five categories. According to subjects' perception, accidents and assaults represent the greatest risks of the profession. It can be inferred that the actions of health education and disease prevention should be governmental and no governmental strategies that would assign value to the health and safety of these workers.

Key Words: Occupational risks; Occupational health; Transportation; Workers.

\section{RESUMEN}

Estudio descriptivo y cualitativo que tuvo como objetivo identificar los riesgos laborales y debilidades auto-reporte por los conductores de motocicletas. Los datos fueron recolectados en el primer semestre de 2010 a través de entrevistas con doce conductores de motocicletas, invitados a participar, y que trabajan en dos puntos centrales de un municipio en el estado de Rio Grande do Sul. Los datos fueran examinados utilizando el análisis temático, que permitió la emergencia de cinco categorías. De acuerdo con la percepción que tienen, los accidentes y asaltos representan los mayores riesgos de la profesión. Se puede inferir que las acciones de educación para la salud y las estrategias de prevención de la enfermedad pueden ser estrategias gubernamentales y no gubernamentales que asignan un valor a la salud y a la seguridad de estos trabajadores.

Palabras clave: Riesgos laborales; Salud laboral; Transportes; Trabajadores. 


\section{INTRODUÇÃO}

A motocicleta representa, no Brasil, um meio de transporte socialmente importante, especialmente para a classe trabaIhadora que a utiliza para condução e/ou para serviços de mototaxi, motoboy ou motofrete. Devido ao custo acessível do veículo e das tarifas de serviço, é um equipamento que facilita a aquisição para a profissionalização e contribui para a mobilidade social.

Tanto nas grandes metrópoles como nas pequenas cidades, observa-se um aumento de serviços alternativos que usam a motocicleta como meio de transporte de mercadorias e de pessoas, compondo uma profissão exposta a agravos decorrentes da exposição a acidentes por causas externas e/ou aos agentes físicos, biológicos e psicossociais. Neste panorama insere-se a atividade do mototaxista.

Ainda não há registro, na Classificação Brasileira de Ocupações, do Ministério do Trabalho e Emprego sobre esta atividade. Apenas o motoboy, sob o número 5191-10 - Motociclista no transporte de documentos e pequenos volumes ${ }^{(1)}$ está registrado como ocupação e com a seguinte descrição: "coletam e entregam documentos, valores, mercadorias e encomendas. Realizam serviços de pagamento e cobrança, roteirizam entregas e coletas. Localizam e conferem destinatários e endereços [...]". Embora as atividades sejam semelhantes, o transporte de pessoas é o que difere uma ocupação da outra, pois o mototaxista tem este, como sua finalidade principal.

A lei 12.009 , de 29 de julho de $2009^{(2)}$, que regulamenta a atividade do mototaxista, legisla sobre idade, carteira de habilitação e obrigatoriedade de ser aprovado em curso especializado para o exercício da profissão, e o Conselho Nacional de Trânsito (CONTRAN) aprovou regras aos cursos obrigatórios para a formação específica desses condutores. Entre outras prerrogativas, esta lei determina o uso de equipamentos de proteção e instalação de equipamentos de segurança nas motos, sendo da competência dos municípios regulamentar e fiscalizar o funcionamento desses serviços.

A legislação contribui para diminuir a precarização do trabalho, afastando-o da clandestinidade, pois as más condições laborais, como os ritmos intensos a que os mototaxistas são submetidos, os expõem ao desgaste e, sobretudo, elevam o risco de se envolverem em acidentes de trânsito, além de originarem distúrbios do sono, fadiga, irritabilidade, sedentarismo, entre outros problemas.

Um estudo realizado no Paraná, Brasil, apontou o cansaçO$^{(3)}$, causado pela sobrecarga, como o principal facilitador do acidente. Esses profissionais se submetem a alternância de turnos e jornadas superiores a 10 horas, situação que pode ocasionar cansaço físico e mental. Quando cansados, há diminuição dos reflexos e da atenção exigida no trânsito.

O trabalho em turnos pode ter efeitos sobre a saúde e incidir sobre a qualidade de vida. Inversões nos turnos de trabalho alteram o ciclo sono-vigília e trazem prejuízos à capacidade funcional(4). Além disso, trabalhar "sob constante pressão do tempo em um contexto que prima pela antecipação das necessidades dos consumidores, o local de trabalho expandido nas vias públicas transforma-se em um universo de controle do tempo", que cria novos modos de ser e de viver na sociedade como "relações de amizade superficiais, tão curtas quanto a passagem do vermelho para o verde nos semáforos da cidade" (5).

Tanto empregadores como clientes geram pressão ${ }^{(3,5)}$ sobre esses trabalhadores que, visando uma melhor produtividade, demandam agilidade e rapidez para cumprimento de metas, favorecendo os acidentes. Essa 'corrida contra o tempo' predispõe à condução da motocicleta em desacordo com as regras de trânsito, tais como aumento da velocidade ou distrações pelo atendimento de celulares pessoais ou rádios, comportamentos que potencializam os riscos.

Isto posto, pode-se perceber que os trabalhadores que utilizam a motocicleta como instrumento de trabalho, expõem-se aos mais diversos riscos sejam físicos, químicos, ergonômicos, biológicos, mecânicos, psicossociais e de acidentes, que decorrem das condições precárias inerentes ao meio ambiente ou do próprio processo operacional de suas atividades, tais como exposição à chuva, sol e frio por tempo prolongado; desgaste físico e emocional em decorrência de fatigantes cargas e ritmos de trabalho; mordida de cães; colisões provocadas por animais em perseguição da moto; dores osteomusculares em virtude de longas horas trabalhando sem conforto ergonômico; e risco de assaltos e violência.

Em um estudo que teve como finalidade discutir a árdua busca de segurança entre trabalhadores motoboys de Salvador, foi verificado que, entre os vitimizados, 56\% da amostra, dois perderam a moto por furto, oito sofreram tentativas de assalto e oito já tinham sido assaltados; entre estes últimos, dois haviam sido vítimas repetidas de assalto $^{(6)}$.

Investigar situações de trabalho, com vistas à atenção integral à saúde, e que visem à redução dos acidentes, promovam segurança e possibilitem a proteção do trabalhador, em todas as formas de organização produtiva, são estratégias que conferem valor à vida.

Emerge, nesta discussão, uma breve reflexão sobre a importância da orientação ao autocuidado destes trabalhadores. Porém, é válido salientar que o fenômeno do autocuidado deve ser pensado em um contexto mais complexo, da relação entre sistema de saúde, profissionais e usuários envolvidos, pois não se configura apenas como um problema de responsabilidade individual. Neste contexto, "é oportuno atentar para a participação social implicada, sobre a qual práticas de autocuidado são entendidas como construções conversacionais produzidas nas relações entre as pessoas" e a interação "é uma ferramenta potencial para contextualização das ações, possibilitando a compreensão das necessidades e demandas locais e a co-construção de alternativas viáveis para solucioná-las"(7)

Incorporar o diálogo nestas situações pode ser estratégico, pois, a partir da interlocução de ações conjuntas entre profissionais e população, pode ser rompida a tradicional divisão nas relações de saber/poder, legitimando assim, outras vivências que envolvem o processo saúde/doença ${ }^{(7)}$. A socialização entre saberes populares, científicos e, nesta conjuntura, políticos, pode ser um mecanismo para a resolução de problemas coletivos. 
Delimitado por este panorama, este estudo justifica-se por pretender provocar uma reflexão acerca dos agravos sofridos pelos mototaxistas no cotidiano de trabalho, e sensibilizar gestores dos setores públicos ou privados, bem como profissionais que atuam em saúde do trabalhador acerca da construção de políticas e estratégias de promoção da saúde e prevenção de doenças decorrentes destas atividades. Sendo assim, teve-se como objetivo identificar riscos ocupacionais e fragilidades autorreferidas pelos sujeitos que desempenham a atividade de mototaxista.

\section{MÉTODOS}

Trata-se de uma pesquisa de caráter descritivo, com abordagem qualitativa.

A coleta de dados foi realizada no primeiro semestre de 2010, junto a 12 trabalhadores mototaxistas de dois pontos centrais de um município do interior do Rio Grande do Sul. A escolha destes locais foi intencional, por conveniência. O serviço de mototáxi do município é constituído por uma estrutura organizacional simples, composta por dois tipos de agentes: o gestor ou "dono" do ponto, quem "aluga" o lugar no qual os profissionais aguardam o chamado e, os mototaxistas, que prestam o serviço de transporte.

Os dados foram coletados por meio de entrevistas semiestruturadas, com a finalidade de beneficiar a livre expressão dos sujeitos e instigar a temática em estudo. As entrevistas foram feitas após convite a todos os sujeitos, em local reservado do posto de trabalho, e gravadas. Posteriormente, foram transcritas na íntegra e analisadas segundo a técnica da análise de conteúdo, na modalidade de análise temática ${ }^{(8)}$.

Para realização deste estudo foram respeitados aspectos éticos da pesquisa envolvendo seres humanos e só iniciado mediante parecer favorável do Comitê de Ética da Universidade Regional Integrada do Alto Uruguai e das Missões, Campus de Santo Ângelo, sob Protocolo n ${ }^{\circ}$ 0046-4/PPH/10, e autorização dos gestores dos pontos de mototaxistas em estudo. Os sujeitos que consentiram em participar assinaram o Termo de Consentimento Livre e Esclarecido. Foi atribuído aos sujeitos da pesquisa o nome fictício de pássaros.

\section{RESULTADOS E DISCUSSÃO}

A transcrição e organização dos relatos obtidos pelas entrevistas com os sujeitos compuseram a ordenação dos dados e a classificação deu-se a partir da leitura exaustiva destes materiais, identificando-se estruturas de relevância, de onde insurgiram cinco categorias: Vantagens e desvantagens da profissão; Riscos e adoecimentos decorrentes da atividade; A opção de ser mototaxista; Melhorias para a profissão concebidas pelos mototaxistas; A nova legislação em evidência.

\section{Caracterização dos sujeitos}

Participaram do estudo doze mototaxistas que trabalham em dois pontos centrais de um município do interior do estado do Rio Grande do Sul. Conforme os dados sócios demográficos levantados, todos eram do sexo masculino, com idade variável entre 25 a 42 anos, possuindo em média 32,5 anos. Destes, 50\% eram solteiros, 33,4\% casados e 16,6\% mencionaram união estável. Correspondem a $41,6 \%$ os que possuíam ensino fundamental incompleto, $25 \%$ ensino fundamental completo, $25 \%$ ensino médio incompleto e $8,4 \%$ com ensino médio completo. Da totalidade $83,3 \%$ possuíam filhos. A carga horária de trabalho de todos os trabalhadores era de 12 a 14 horas diárias, nos turnos manhã, tarde e noite. Dos doze entrevistados, 25\% possuía outra atividade remunerada, tais como músico, entregador de cargas em caminhão e vigilante.

Importante é considerar que estes sujeitos trabalham mais de oito horas por dia, o que os torna vulneráveis ao declínio da qualidade de vida e de saúde, considerando-se a longa jornada de trabalho. Mais de um terço são casados e grande parte possui filhos, o que aponta sua responsabilidade e/ou corresponsabilidade pelo sustento de famílias. Outro dado significativo refere-se aos anos de estudo; a grande maioria possui o ensino fundamental e incompleto, tornando-os frágeis à conquista de melhores postos de trabalho.

\section{Vantagens e desvantagens da profissão}

Grande parte dos sujeitos referiu que a maior desvantagem do trabalho do mototaxista é não possuir carteira assinada, como se pode observar nos relatos:

A desvantagem, também, o problema é que não tem carteira assinada, esse é o único problema, que não tem[...], o salário é bom, só a desvantagem é que não tem carteira assinada. (Cardeal)

A desvantagem é que tu não, como se diz que Deus o livre sofra um acidente tu não tem como, por exemplo, assim, nós não pagamos 'INPS', então daí no caso se sofre um acidente seria tudo por nossa conta então seria essa as desvantagens, né. (Sabiá Laranjeira)

A legislação trabalhista brasileira regulamenta que somente tem direito ao auxílio-acidente, ou seja, ao benefício pago ao trabalhador que sofre um acidente e fica com sequelas que reduzem sua capacidade de trabalho, aquele que tenha a qualidade de segurado ${ }^{(9)}$. Sendo assim, o vínculo informal e/ou a inexistência de vínculo trabalhista, caracterizado pelo falta de registro em Carteira de Trabalho e Previdência Social e que Ihe imputa a condição de contribuinte, inviabiliza que ele usufrua desse e de outros benefícios, tais como direito a férias, décimo terceiro salário, aposentadoria, licença remunerada por doença e regulação da jornada e turno de trabalho.

Um estudo junto a motoboys denunciou que a grande maioria não possuía registro em carteira, o que pode ser explicado pela forma de organização do trabalho vigente ${ }^{(10)}$. A falta de assistência e o não recebimento de qualquer benefício em caso de acidente foi uma das preocupações relatadas pelos sujeitos, semelhantes aos dados desta pesquisa.

Uma das vantagens da atividade de mototaxista, antagonicamente a outras ocupações que implicam em subordinação ao empregador, jornadas rígidas no cumprimento de horários, 
metas a alcançar, é a liberdade que a profissão oferece, além da autonomia e do horário flexível, conforme as falas da maioria dos entrevistados:

A vantagem é que tu trabalha livre, né, a hora que a gente quer; não tem ninguém mandando, tu vai para qualquer lugar se quiser. Hoje sai para outra cidade, se quiser ficar um mês em casa tu fica; tu não é obrigado, entende? (Bacurau)

As vantagens é que tu trabalha livre, o horário que quer fazer, não trabalha final de semana, não trabalha, só dia de semana[...]. (Diamante de Goldi)

A vantagem de ser 'mototáxi' é que fica meio livre, né, não tem muita gente cobrando se chega no horário ou sai no horário[...]. (Mandarim)

Em concordância com estes dados, estudos apontam que as principais vantagens da profissão, segundo os motoboys, são a sensação de liberdade, a oportunidade de conhecer novos lugares e pessoas e, principalmente, a autonomia, além da remuneração, que é assinalada como condição favorável ao exercício da profissão ${ }^{(10,11)}$.

\section{Riscos e adoecimentos decorrentes da atividade}

Entre os riscos que os mototaxistas percebem no cotidiano de trabalho, todos os entrevistados evidenciaram o risco de acidente de trânsito e de assalto.

O risco é muito grande, o risco de ser assaltado, risco de acidente. Daí tu não tem nenhuma escora, nem nada, não tem carteira assinada, entendeu?No momento em que tu sofre um acidente ou for assaltado, tu mesmo assume teus próprios riscos, é assim, a vida de mototaxi não tem outro jeito [...].(João de Barro)

Risco é o trânsito e o problema do assalto. Falta de segurança nos bairros, é isso. (Cardeal)

[...] risco maior é assalto e o outro é acidente, o pessoal corta a frente da gente bastante. Esse é o problema maior, os dois [...].(Miudinho)

O desrespeito e a desatenção por parte dos motoristas, condição inadequada da infraestrutura viária, tráfego com chuva, despreparo do motociclista, excesso de velocidade, fadiga e más condições do veículo são fatores que influenciam nos riscos de acidentes ${ }^{(10,12,13)}$. Além disso, o arranjo estrutural da motocicleta pode ter alguma influência na ocorrência dos acidentes, considerando que há proteção insuficiente no veículo, expondo o motociclista a todo tipo de impacto.

Um estudo realizado em Alberta (CA) concluiu que motociclistas têm mais de 3,5 vezes chances de se ferir ou morrer em acidentes, que outros condutores de veículos a motor ${ }^{(14)}$. O impacto gerado para a economia do sistema de saúde também foi um dado significativo gerado por aquela pesquisa, considerando que os motociclistas representaram 10.760 dias acamados e, admitindo-se que o paciente não seja internado em unidade de tratamento intensivo, a internação gerava, em 2008, um custo de 9.200 dólares.

Os dados de uma pesquisa realizada no Irã demonstraram que o perfil relacionado aos fatores de risco de acidente com motocicleta envolve ser jovem e solteiro, viver em condições socioeconômicas mais baixas e em más condições de saúde física e mental. Além disso, dificuldades no trânsito, estradas inseguras, carros e motoristas agressivos foram alguns dos fatores apontados como facilitadores da ocorrência de acidentes nesta pesquisa, ${ }^{(15)} \mathrm{O}$ que demostra que os fatores de risco para o acidente de trânsito são semelhantes tanto em cenários nacionais como internacionais.

Outro risco constante referido pela maioria dos sujeitos é o assalto. Um estudo realizado na Amazônia identificou que devido aos assaltos sofridos, a maioria dos trabalhadores passou a não trabalhar no período noturno ou madrugada, e limitaram o transporte de alguns passageiros a determinados locais das cidades com menores índices de violência; alguns dos assaltos ocorriam após o mototaxista transportar o sujeito até o local solicitado ${ }^{(12)}$.

Com o objetivo de descrever as características dos atendimentos de emergência por agressões uma pesquisa revelou que homens são mais vitimados que mulheres sendo a agressão física o tipo predominante, por uso de força corporal/espancamento, em via pública, com maior frequência entre o início da noite e final da madrugada e cometida por desconhecidos ${ }^{(16)}$, conjuntura que pode incluir o mototaxista como vítima. Muitos destes trabalhadores perdem moto, carga transportada e dinheiro em decorrência de assaltos à mão $\operatorname{armada}^{(10)}$. Assim, muito além da violência configurada pelo assalto, há a preocupação com o roubo da motocicleta, um patrimônio pessoal e, importante instrumento de trabalho e sobrevivência ao trabalhador e aos familiares dependentes.

É válido ressaltar que, em concordância com esta pesquisa, trabalhadores indagados no Rio de Janeiro $(R J)^{(11)}$ e em Porto Alegre (RS) ${ }^{(13)}$ consideram sua profissão perigosa ou arriscada. Dos respondentes na nossa pesquisa, 66,6\% expuseram que a profissão de mototaxista é insegura e arriscada, embora alguns a considerem relevante para a segurança financeira da família.

É segura no sentido de renda, é segura com certeza, mas tem bastantes riscos[...] o trânsito é bastante violento [e há] o assalto. Essa é a desvantagem, esse é o risco que a gente corre todos os dias. (Caraxué)

Olha, mototáxi é o seguinte: não tem como te dizer que é uma atividade segura né, porque no momento que a gente sai, a gente está arriscando, sofre um acidente, acomete um acidente, então, né, não tem como dizer que tenha uma segurança no caso [...]. (Sabiá Laranjeira)

Não tem segurança nenhuma, porque a gente está sujeito a qualquer coisa, a qualquer momento, se tem o máximo de cuidado, não tem segurança nenhuma segurança não tem 
nada, mototáxi é um serviço aventura na verdade, serviço de aventura não tem segurança nenhuma. (João de Barro)

Em se tratando de segurança à saúde, outro fator que merece atenção é a exposição destes condutores aos riscos físicos, característicos do calor e frio intenso. O estado do Rio Grande do Sul possuiu as quatro estações do ano bem definidas, sendo o inverno muito rigoroso. Trabalhar como mototaxista implica em expor-se a variações climáticas intensas durante o dia e à noite, agravantes às boas condições saúde. Assim sendo, podem surgir doenças como gripe, dor de garganta, resfriado, bronquite, conforme relato de $83,3 \%$ dos sujeitos respondentes da pesquisa.

Só a gripe, né, a gripe está junto com o motoqueiro sempre, inverno e verão; no verão também, claro se tu está de noite, assim, cai a noite e refresca; daí tu está mal vestido, vamos dizer, de camiseta, bermuda; daí tu pega aquele ar da noite e pegar uma gripe de verão é pior que a do inverno.(Saí Azul)

[...] to tosse. Peguei uma tosse e uma bronquite assim, que não tem cura, sabe, eu tomo remédio, consulto e é só no inverno. Tomei tudo que é tipo de remédio porque eu trabalho bastante de noite, né. (Bacurau)

[...] gripe, resfriado, dor de garganta geralmente no inverno.(Príncipe)

Muitos mototaxistas trabalham doentes ou com mal estar físico, a fim de cumprir com seus compromissos financeiros, o que agrava o problema. Sabe-se que dificuldades relacionadas ao próprio transporte, carga horária elevada e a precariedade das condições de trabalho são alguns dos fatores que contribuem para o sofrimento e adoecimento tais como o cansaço, as dores no corpo, o calor, o sono, o medo e o estresse ${ }^{(12)}$.

Além disso, os Equipamentos de Proteção Individual (EPI) utilizados por estes trabalhadores no desenvolvimento de suas funções restringem-se ao capacete, que muitas vezes gera mais calor, e as capas de chuva, que úmidas facilitam a exposição às doenças respiratórias.

A legislação menciona os EPI que protegem os trabalhadores contra riscos de acidentes; mas não se refere a dispositivos para o enfrentamento de outros riscos, tais como a chuva ou a violência $^{(2)}$. Conforme a lei $n^{\circ} 12.009 / 09$, os mototaxistas devem usar colete de segurança com dispositivo refletivo e instalar equipamentos de segurança nas motos, tais como "protetor de motor mata-cachorro, fixado no chassi do veículo, destinado a proteger o motor e a perna do condutor em caso de tombamento [...] e aparador de linha antena corta-pipas." É válido ressaltar que, mesmo já sendo obrigatória a utilização destes equipamentos, persiste a negligência por parte dos profissionais e dos órgãos fiscalizadores.

Percebeu-se que alguns entrevistados desconhecem os EPI recomendados pela lei; dos 58,33\% dos entrevistados que já sofreram acidente durante o exercício da profissão, todos enfatizaram que usavam apenas o capacete como meio de proteção.
Já sofri acidente de trânsito uma vez nesse tempo que eu trabalho e o equipamento de segurança que eu usava era o capacete, no momento da colisão que eu sofri o acidente. (Sangue de Boi)

Sofri dois acidentes, mas o equipamento que eu estava usando era o capacete, só o capacete nada mais, só o capacete. (João de Barro)

Eu já sofri um acidente[...] usava só o capacete, no caso, que é um item obrigatório e necessário também, né. (Andorinha)

Dados de um estudo realizado em Porto Alegre com motociclistas profissionais, apontou que cerca de $80 \%$ dos entrevistados já haviam sofrido mais de um acidente enquanto conduziam motocicleta a trabalho, sendo que $100 \%$ utilizavam o capacete $^{(13)}$. Ainda, 93\% utilizavam roupas especiais de proteção contra chuva, 54\% usavam luvas, 32\% cotoveleiras e apenas $17 \%$ joelheiras. De acordo com uma investigação realizada no município de Uberaba-MG, nos acidentes motociclísticos a que os sujeitos foram expostos, 68,37\% faziam uso do capacete no momento do acidente ${ }^{(17)}$. Este dado é preocupante, considerando que mais de $30 \%$ não usavam nem este EPI, tão cobrado pelas autoridades que regulam o trânsito, além de que, sem o capacete, a exposição ao traumatismo crânioencefálico é muito maior, em caso de acidente.

\section{A opção de ser mototaxista}

Mesmo diante dos riscos e das desvantagens que a profissão de mototaxista detém, 66,6\% dos entrevistados responderam que desejam continuar com a atividade, conforme relatos:

Pretendo continuar porque a gente no 'mototáxi' tira bem mais que fosse trabalhar numa firma, assim, na firma trabalha num horário, mas no 'mototáxi' a gente trabalha um pouquinho mais, mas o rendimento é bem melhor também [...]. (Sangue de Boi)

Sim, pretendo continuar porque não tem serviço na cidade, não tem emprego, né, as empresas são devagar. (Cardeal)

Sim, eu pretendo porque faz tempo que nós estamos nessa lida lutando. Faz 13 pra 14 anos já e estamos aí,, é um meio de trabalho pra nós sobreviver, né, porque emprego está muito difícil[...]. (Miudinho)

O que se observou é que esses profissionais permanecem na profissão pela falta de opção de trabalho, por ser um meio de sobrevivência e de sustento à família, com um retorno financeiro razoável para suas necessidades pessoais, além de que a maioria não possui anos de estudo suficientes para competir no mercado de trabalho. Uma pesquisa confirmou esses dados, identificando que, apesar dos riscos, a maioria dos motoboys continua exercendo a profissão por necessidade ou por falta de outras opções de trabalho, e justificam os riscos assumidos no exercício de suas atividades por conta da remuneração obtida ${ }^{(10)}$. 


\section{Melhorias para a profissão concebidas pelos motoxistas}

Apesar dos vários benefícios trazidos pela atividade de mototaxista, esses trabalhadores convivem com condições precárias de trabalho, ritmos intensos, carga horária desgastante, riscos de acidentes e assaltos. Tais condições podem ser deletérias para a saúde.

Os trabalhadores foram indagados quanto às melhorias que poderiam ser realizadas para beneficiá-los e a resposta que se destacou foi a necessidade de regulamentação da profissão, referenciada por $58,3 \%$ dos sujeitos, seguida de segurança para o profissional, como observado a seguir.

Teria que haver uma regularização aí, né, que ao mesmo tempo em que a gente ande na rua a gente tenha também uma segurança no sentido de ter os nossos direitos[...]. (Sabiá Laranjeira)

A princípio, a legalização né, que com a legalização, 'passa a ficha corrida', fica só aqueles adequados né, competentes e também mais atenção da brigada com os motoqueiros. (Caraxué)

Já está em andamento o procedimento pra regularização do mototaxista pra ser uma firma registrada, vai ser mais tardar final do ano, vai se regulamentado, vai ser um uma firma registrada, daí não vai ser mais 'frio assim, um trabaIho frio'. (Sangue de Boi)

É dá mais segurança pra nós, é aumentar policiamento nos bairros, por exemplo, não adianta ter módulo de brigada nos bairros e não ter brigadiano nenhum, nenhuma viatura, nada nos módulos, né. Se tu passa, chega nos bairros mais visados aí, que tem, inclusive, os módulos, mas não tem brigada, no momento[...]. (João de Barro)

\section{A nova legislação em evidência}

A motocicleta é um veículo de custo acessível, tanto para a aquisição quanto para a manutenção e tornou-se um instrumento de trabalho muito relevante, o que contribui para uma melhor rentabilidade e inclusão social do trabalhador, porém, a profissão de mototaxista é exercida, ainda, na clandestinidade, considerando-se que apenas recentemente a profissão foi regulamentada ${ }^{(2)}$.

Noticiado pela mídia, vários municípios tentaram proibir a profissão, sem êxito, ou editar normas, regulamentando a atividade. A questão sempre foi polêmica, recheada de argumentos favoráveis, ligados à questão social e contra, associando-o à insegurança do transporte, aos acidentes e/ou ao favorecimento da criminalidade, na facilitação do tráfico de entorpecentes, o que deve relativizado, pois o que se observou no decorrer deste estudo foi que muitos desses trabalhadores são, numa análise preliminar e subjetiva, sujeitos que, arduamente, estão lutando por sua sobrevivência e a de seus familiares.

Conforme já citado, a lei federal 12.009, que dispõe sobre a atividade de mototaxista, prevê que cada município deve criar suas leis específicas para regulamentar a profissão seguindo as diretrizes determinadas na legislação federal ${ }^{(2)}$. No município em estudo, desde 2005 estas normas de organização do serviço estão sendo discutidas pelo legislativo e, com a aprovação da referida lei federal, novamente há um debate em torno da regulamentação municipal, porém nada ainda foi feito.

Contudo, embora anseiem pela regulamentação, este assunto ainda é um enigma para muitos dos sujeitos pesquisados, ainda há insegurança sobre suas vantagens ou desvantagens, como demonstram as falas:

Eu não estou muito por dentro do assunto, sabe, entendeu? Eu não entrei muito $100 \%$ no assunto, entendeu? É favorável, se a regularização é deles entendeu?[...] e se não ajudarem em nada ? é preferível deixar assim, cada um se vira do jeito que pode. (Andorinha)

Pois é, vai favorecer acho que o negócio de tu poder assinar a carteira, vamos dizer assim, paga um'INPS', como motoboy mesmo né, o que vai desfavorecer é esse negócio de comprar a moto, vou te que trocar a minha moto. (Saí Azul)

Favorável é que vai ser tipo identificado com colete, sobre qual ponto que a pessoa trabalha e vai ter um curso de aperfeiçoamento e desfavorável, tipo, de repente em torno do valor que vai ser estipulado o valor $x$ da corrida dentro da cidade. (Sangue de Boi)

É eu nem sei o que vai se favorável e o que vai ser desfavorável,porque não sei o que está acontecendo sobre isso aí[...] (Mandarim)

De acordo com a legislação federal, algumas das exigências para exercer a profissão são: passar por cursos de formação específica, ter idade mínima de 21 anos e habilitação específica para motocicletas há pelo menos dois anos ${ }^{(2)}$. Os que já estão na profissão têm até um ano para se adaptar às novas regras exigidas para essas atividades.

Foi publicada em 4 de agosto de 2010 a Resolução No 356 do Conselho Nacional de Trânsito (CONTRAN), que institui requisitos de segurança para o transporte remunerado de passageiros e de cargas em motocicleta e motoneta ${ }^{(18)}$, complementando a Lei 12.009. Segundo esta Resolução, para realizar o registro, os veículos deverão estar dotados de equipamento de proteção para pernas e motor, aparador de linha e dispositivo de fixação permanente ou removível para o passageiro ou para a carga. Os motociclistas profissionais e passageiros deverão utilizar capacete, com viseira ou óculos de proteção e faixas retrorrefletivas. Além disso, o condutor deverá estar vestido com colete de segurança dotado de dispositivos retrorrefletivos, o que contribui para a prevenção de alguns riscos ocupacionais.

Os motociclistas profissionais terão até quatro de agosto de 2011 para se adequarem às normas da Resolução 356 do Conselho Nacional de Trânsito (CONTRAN) e aos demais requisitos da Lei 12.009. A Resolução no 350 de 14 de junho de $2010^{(19)}$, institui curso especializado obrigatório destinado aos profissionais em transporte de passageiros (mototaxista) e em entrega de mercadorias (motofretista) que exerçam atividades remuneradas na condução de motocicletas e motonetas. 
Isto posto, algumas estratégias podem ser arraigadas com a finalidade de promover a saúde e a cidadania deste trabaIhador. Iniciativas de regulamentação da profissão podem ser fecundas, na medida em que os tira da "clandestinidade trabalhista", porém, acima de tudo, investimentos em cursos, em educação que trate de aspectos de legislação, de trânsito, de cidadania e de segurança e saúde são fundamentais, especialmente se conduzidos em linguagem acessível a todos e que envolva a participação dos sujeitos como atores constitutivos do processo de educação, mediante efetiva comunicação seja ela verbal, escrita e/ou ilustrativa.

Materiais escritos podem configurar-se como uma contribuição preciosa para se favorecer a autonomia do indivíduo, além de que o uso de figuras pode ser atraente e agir como um facilitador da compreensão do texto ${ }^{(20)}$. Sendo assim, a construção de cartilhas de forma coletiva pode ser uma alternativa, que, socializada junto aos grupos de trabalhadores, gestores e profissionais, pode conectá-los numa mesma única meta: produzir saberes para prevenir e promover.

\section{CONSIDERAÇÕES FINAIS}

Esta investigação mostrou a relevância de concretizarem-se políticas públicas de promoção da saúde dos trabalhadores mototaxistas, visto que esses sujeitos exercem suas atividades em condições precárias inerentes ao ambiente, tais como exposição ao sol, chuva, desgaste físico, emocional, e, principalmente, a risco de assalto e acidentes de trânsito, conforme se evidenciou nos dados coletados. Estas são condições de insegurança no trabalho, capazes de comprometer a saúde, a segurança e o bem estar do trabalhador.

Diante das grandes dificuldades e perigos a que os mototaxistas são expostos diariamente, são necessárias estruturas e dispositivos públicos que envolvam ações de segurança, dignidade e cidadania destes trabalhadores e que permitam o prosseguimento do exercício profissional.

Acredita-se que, compartilhando uma cultura de educação em segurança, usuários, trabalhadores, governos, meio de comunicação, profissionais da saúde, polícia, entre outros, se tornam co-atores no processo que intenta minimizar, senão possível anular a ocorrência de agravos decorrentes dos acidentes e assaltos, um dos grandes problemas enfrentados por estes profissionais.

Sugerem-se estudos que possam, mediante metodologias participativas, envolver os profissionais em discussões problematizadoras, de modo a auxiliar na criação de mecanismos de formação de associações representativas, a fim de emancipar a profissão e as discussões sobre a categoria, também nos cenários do interior dos estados, garantindo o exercício pleno saudável de suas atividades.

\section{REFERÊNCIAS}

1. Ministério do Trabalho e Emprego(BR). Portaria no 397, de 09 de outubro de 2002 Aprova a Classificação Brasileira de Ocupações - CBO/2002 [internet]. 2002 [citado 2010 mar 15]. Disponível em: http://www.mtecbo.gov.br/ cbosite/pages/legislacao.jsf.

2. Presidência da República (BR). Casa Civil. Subchefia para Assuntos Jurídicos. Lei 12.009, de 29 de julho de 2009. Regulamenta o exercício das atividades dos profissionais em transporte de passageiros, "mototaxista", em entrega de mercadorias e em serviço comunitário de rua, e "motoboy", com o uso de motocicleta [internet]. 2009 [citado 2010 abr 20]. Disponível em: http://www.planalto.gov.br/ ccivil_03/_Ato2007-2010/2009/Lei/L12009.ht.m

3. Silva DV, Andrade SM, Soares DA, Soares DFPP, Mathias TAF. Perfil do trabalho e acidentes de trânsito entre motociclistas de entregas em dois municípios de médio porte do Estado do Paraná, Brasil. Cad. Saúde Pública 2008; 24(11):2643-52.

4. Lima AMJ; Soares CMV. Souza AOS. Efeito da inversão dos turnos de trabalho sobre capacidade aeróbia e respostas cardiovasculares ao esforço máximo. Rev Bras Med Esporte 2008; 14(3): 201-4.

5. Grisci CLI, Scalco PD, Janovik MS. Modos de trabalhar e de ser de motoboys: a vivência espaço-temporal contemporânea. Psicol. Cienc. Prof. 2007; 27(3):446-461.

6. Paes-Machado E, Riccio-Oliveira MA. O jogo de esconde-esconde: trabalho perigoso e ação social defensiva entre motoboys de Salvador. Rev. Bras. Ci. Soc. 2009; 24(70): 91-106.

7. Camargo-Borges $\mathrm{C}$, Japur M. Sobre a (não) adesão ao tratamento: ampliando sentidos do autocuidado. Texto Contexto-Enferm. 2008;17(1): 64-71.

8. Minayo MCS. O desafio do conhecimento: pesquisa qualitativa em saúde. $7^{a}$ ed. São Paulo: Hucitec; 2008.

9. Ministério da Previdência Social. Auxílio-acidente [internet]. 2010 [citado 2010 jul 12]. Disponível em: http:// www.mpas.gov.br/buscaGeral.php.

10. Silva DW, Andrade SM, Soares DA, Nunes EFPA, Melchior R. Condições de trabalho e riscos no trânsito urbano na ótica de trabalhadores motociclistas. Physis Revista de Saúde Coletiva 2008; 18 (2): 339-60.

11. Fonseca NRR. Sobre duas Rodas: o mototáxi como uma invenção de mercado. [dissertação]. Rio de Janeiro (RJ): Programa de pós-graduação em Estudos Populacionais e Pesquisas Sociais da Escola Nacional de Ciências Estatísticas; 2005.

12. Salim Filho MT. Demandas e Políticas Públicas de Transporte Urbano [dissertação]. Belém (PA): Universidade Federal do Pará, Núcleo de Altos Estudos Amazônicos; 2007.

13. Ferreira FF. Fatores de risco em acidentes envolvendo motocicletas em vias urbanas: a percepção dos condutores profissionais [dissertação]. Porto Alegre (RS): 
Universidade Federal do Rio Grande do Sul, Escola de Engenharia, Programa de Pós-Graduação em Engenharia de Produção; 2009.

14. Monk JP, Buckley R, Dyer D. Motorcycle-related trauma in Alberta: a sad and expensive story. Can JSurg. [internet]. 2009 [citadoem 2010jul 19]; 52(6):E235-40. Availablefrom:http:// business.highbeam.com/435674/article-1G1-213777792/ motorcyclerelated-trauma-alberta-sad-and-expensive.

15. Zamani-Alavijeh F, Niknami S, Bazargan M, Mohamadi E, Montazeri A, Ghofranipour F et. al. Risk-taking behaviors among motorcyclists in middle east countries: a case of Islamic Republic of Iran. Traffic Inj Prev.[internet]. 2010 [citado em 2010 jul 19]; 11(1):25-34. Available from: http://www.ncbi.nlm.nih.gov/pubmed/20146140.

16. Mascarenhas MDM, Pedrosa AAG. Atendimentos de emergência por violência em serviços públicos de Teresina, PI. Rev Bras Enferm 2008 ; 61(4): 493-99.

17. Silva DP, Barbosa MH, Chavaglia SRR. Utilização de equipamentos de segurança entre vítimas de acidentes no município de Uberaba-MG Rev. Eletr. Enf.[internet]. 2010 [citado 2010 jul 12];12(1):83-8. Disponível em: http:// www.fen.ufg.br/revista/v12/n1/v12n1a10.htm.

18. Departamento Nacional de Transito (BR). Resolução $n^{\circ}$ 356, de 02 de agosto de 2010. Estabelece requisitos mínimos de segurança para o transporte remunerado de passageiros (mototáxi) e de cargas (motofrete) em motocicleta e motoneta [internet]. 2010. [citado em 2010 out 20]. Disponível em: http://www.denatran.gov.br/download/ Resolucoes/RESOLUCAO_CONTRAN_356_10.pdf.

19. Departamento Nacional de Transito (BR).Resolução $n^{\circ}$ 350 de 14 de junho de 2010.Institui curso especializado obrigatório destinado a profissionais em transporte de passageiros (mototaxista) e em entrega de mercadorias (motofretista) que exerçam atividades remuneradas na condução de motocicletas e motonetas [internet]. 2010 [citado 2010 jun 11]. Disponível em: http://www.denatran.gov.br/download/Resolucoes/RESOLUCAO_CONTRAN 350 10.pdf.

20. Torres HC, Candido NA, Alexandre LR, Pereira FL. O processo de elaboração de cartilhas para orientação do autocuidado no programa educativo em Diabetes. Rev Bras Enferm 2009; 62(2): 312-16. 